\title{
A multicenter prospective phase II randomized trial of epirubicin/vinorelbine versus pegylated liposomal doxorubicin/vinorelbine as first-line treatment in advanced breast cancer. A GOIM study
}

\author{
Patrizia Vici ${ }^{1 *}$, Giuseppe Colucci ${ }^{2}$, Francesco Giotta ${ }^{2}$, Domenico Sergi ${ }^{1}$, Gianfranco Filippelli ${ }^{3}$, Pasquale Perri ${ }^{4}$, \\ Claudio Botti ${ }^{4}$, Enrico Vizza ${ }^{5}$, Armando Carpino ${ }^{6}$, Laura Pizzuti ${ }^{1}$, Agnese Latorre ${ }^{2}$, Diana Giannarelli ${ }^{7}$, \\ Massimo Lopez ${ }^{1}$ and Luigi Di Lauro ${ }^{1}$
}

\begin{abstract}
Background: To evaluate activity and tolerability of two anthracycline-containing regimens as first-line treatment for anthracycline-naïve relapsed breast cancer patients.

Methods: Patients with relapsed breast cancer not previously treated with adjuvant anthracyclines were randomly assigned to epirubicin/vinorelbine (arm A: EPINNB, EPI $90 \mathrm{mg} / \mathrm{m}^{2}$ on day 1 , VNB $25 \mathrm{mg} / \mathrm{m}^{2}$ on days 1,5 plus G-CSF subcutaneously on days 7-12, with cycles repeated every 21 days), or to pegylated liposomal doxorubicin/NNB (arm B: PLDNNB, PLD $40 \mathrm{mg} / \mathrm{m}^{2}$ on day $1, V N B 30 \mathrm{mg} / \mathrm{m}^{2}$ on days 1 , 15, with cycles repeated every 4 weeks). Primary objective was to evaluate the efficacy of the two regimens in terms of response rate, secondarily toxicity, progression free survival and overall survival.

Results: One hundred and four patients have been enrolled (arm A 54, arm B 50): characteristics were well balanced between the 2 arms. Responses were as follows: arm A, 3 (5.6\%) CR, 20 (37\%) PR, (ORR 42.6\%, 95\%Cl 29.3\%-55.9\%); arm B, 8 (16\%) CR, 18 (36\%) PR, (ORR 52\%, 95\%Cl 38.2\%-65.8\%). Median progression free survival was 10.7 months in arm $A(95 \% \mathrm{Cl}, 8.7-12.6)$, and 8.8 months in $\operatorname{arm~B~}(95 \% \mathrm{Cl}, 7.1-10.5)$. Median overall survival was 34.6 months in arm $\mathrm{A}(95 \% \mathrm{Cl}, 19.5-49.8)$ and 24.8 months in $\operatorname{arm~B~}(95 \% \mathrm{Cl}, 15.7-33.9)$. As toxicity concerns, both treatment regimens were well tolerated; myelosuppression was the dose-limiting toxicity, with G3-4 neutropenia occurring in $18.5 \%$ and $22 \%$ of the patients of arm A and B, respectively. No relevant differences in main toxic effects have been observed between the two arms, except for alopecia, more common in arm A, and cutaneous toxicity, observed only in arm B. No clinical congestive heart failures have been observed, one case of tachyarrhythmia was reported after the last EPI/NNB cycle, and two reversible $\geq 20 \%$ LVEF decreases have been observed in arm A.
\end{abstract}

Conclusions: Both anthracycline- containing regimens evaluated in the present study seem to be active and with a satisfactory tolerability in anthracycline-naïve relapsed breast cancer patients.

\footnotetext{
* Correspondence: pvici@ifo.it

'Division of Medical Oncology B, Regina Elena National Cancer Institute, Rome, Italy

Full list of author information is available at the end of the article
} 


\section{Background}

Anthracyclines are among the most active drugs in advanced breast cancer, with response rates as single agents of approximately $30 \%$ to $50 \%$, and anthracyclinebased regimens have been shown to determine significant advantages in response rate and progression free survival over non- anthracycline-containing regimens [1,2]. The potential benefit of conventional anthracyclines, mainly doxorubicin, is limited by the risk of cardiac dysfunction, clearly related to cumulative dose, and as a result it might be necessary to withdraw treatment or to avoid re-treatment even in potential responders patients.

To minimize toxic effects, doxorubicin has often been replaced by epirubicin (EPI), known to be as active as the parent compound and with lower toxicity, particularly cardiac toxicity [3-6]. As dose-response concerns, higher EPI doses, both as single agent and in combination regimens, seem to be more efficacious than lower doses [7-10].

Vinorelbine (VNB) has established activity as singleagent in breast cancer, both as first-line and salvage treatment $[11,12]$, and its good tolerance profile makes it an excellent candidate for combination regimens, so it was a logical step to combine VNB with anthracyclines, and the combination with doxorubicin yielded a $74 \%$ of response rate, a median duration of response of 12 months and a median survival of 27.5 months as first-line treatment [13]. Other trials employing this combinations confirmed positive results [14-16]. Preliminary results of a randomized phase III trial comparing VNB $25 \mathrm{mg} / \mathrm{m}^{2}$ on days 1,8 in combination with EPI $90 \mathrm{mg} / \mathrm{m}^{2}$, with EPI as single agent, showed a trend for higher response rate (50\% vs $42 \%)$ and a significantly longer progression free survival (10.1 vs 8.2 months) for the combination arm [17]. An our previous clinical study with EPI/VNB combination as first-line treatment showed a very high activity $(70.6 \%$ of response rate) and acceptable toxicity [18]; another our experience testing the sequential administration of docetaxel for 4 cycles followed by 4 cycles of EPI/VNB as first-line treatment for advanced disease, confirmed activity and tolerability of the regimen [19].

Incapsulating drugs in liposomes determine improvement of solubility and stability of the drug, and prevent a rapid degradation; moreover, specific toxicities are potentially lowered and the efficacy increased, achieving a higher therapeutic index [20]. Liposomal anthracyclines exhibit efficacies comparable with those of conventional anthracyclines, but with better safety profiles [21-24]. In particular, data from retrospective analyses showed that liposomal anthracyclines significant reduced the risk of cardiotoxicity compared with conventional anthracyclines [25]. Phase III trials comparing pegylated liposomal doxorubicin (PLD) with conventional anthracyclines confirmed similar efficacy and lower toxicity than doxorubicin $[24,26]$, and results of several studies have shown that PLD is effective in combination with other drugs including taxanes, cyclophosphamide, gemcitabine [27]. As cardiotoxicity concerns, in a retrospective analysis a low incidence of cardiac side effects were reported, even at cumulative doses higher than $500 \mathrm{mg} / \mathrm{m}^{2}$ [28]. The combination of PLD with VNB was investigated in anthracycline pretreated patients, with promising results and manageable toxicity $[29,30]$, but at the time we design the present study no information about its firstline use in comparison with a conventional anthracycline-containing regimen were available, so we carried out a prospective multicenter phase II randomized trial of EPI/VNB versus PLD/VNB as first-line treatment for advanced disease in patients not previously treated with adjuvant anthracyclines.

\section{Patients and Methods \\ Patient selection}

Patients with histologically proven advanced breast cancer not previously treated with adjuvant anthracyclines were enrolled. Eligibility criteria included a life expectancy $>$ 3 months, 18 to 75 years of age, WHO performance status $\leq 3$, measurable/assessable disease, adequate bone marrow (absolute neutrophil count $\geq 1,500$, platelet count $\geq$ 100,000 , haemoglobin $\geq 11 \mathrm{~g} / \mathrm{dL}$ ), renal and liver function (total bilirubin and creatinine $<1.25$ times the upper normal limits), and a normal cardiac function (left ventricular ejection fraction LVEF $\geq 50 \%$ by echocardiography). Patients were excluded from the study if they had active cardiac diseases or significant arrhythmias, pre-existent neuropathy, or had received prior chemotherapy treatment for advanced disease, prior exposure to anthracyclines and or vinorelbine, or if they had prior or concomitant malignant disease, except appropriately treated basal cell carcinoma of the skin or in situ carcinoma of the cervix. Previous adjuvant chemotherapy with cyclophosphamide, methotrexate, fluorouracil or similar regimens were allowed, but an interval of two months should have elapsed; hormonal adjuvant treatment and radiotherapy must have been discontinued for at least 4 weeks before study entry. The protocol was approved by the ethical committees of each participant centers, and was carried out according to Helsinki declaration and in accordance with the International Conference on Harmonization Good Clinical Practice guidelines.

\section{Treatment}

Patients were centrally assigned according to a computer generated random list to receive either ( $\operatorname{arm~A}$ ) EPI $90 \mathrm{mg} / \mathrm{m}^{2}$ i.v. on day 1 plus VNB $25 \mathrm{mg} / \mathrm{m}^{2}$ i.v on days 1 and 5, with granulocyte colony-stimulating factor 
(G-CSF) subcutaneously on days 7-12 of each cycle, or (arm B) PLD $40 \mathrm{mg} / \mathrm{m}^{2}$ i.v. on day 1, plus VNB $30 \mathrm{mg} /$ $\mathrm{m}^{2}$ on days 1 and 15 . Cycles were repeated every 21 days in arm A, and every 28 days in arm B, for a maximum of 8 cycles. Treatment was continued until disease progression, severe toxicity, patient refusal. Antiemetic treatment consisted of an antiserotonin agent plus desamethasone in a 15 min infusion before starting chemotherapy. Treatment was postponed by a maximum of 2 weeks if the absolute neutrophil count was less than $1,500 / \mu \mathrm{L}$ or the platelet count was less than $100,000 / \mu \mathrm{L}$. A $25 \%$ drugs dose-reduction was planned in case of grade 4 neutropenic fever, as well as in case of grade 3 mucositis or neurotoxicity. G-CSF was administered in arm B in case of grade 4 neutropenic fever, and prophylactively in the subsequent cycles. Treatment was discontinued in case of grade 4 neurotoxicity, mucositis, palmar plantar erythrodisesthesia (PPE), treatment delay longer than 2 weeks, or in case of cardiotoxicity, defined as LVEF decrease $\geq 20 \%$ from baseline, or $\geq 10 \%$ but with a value below $50 \%$, or any symptoms of congestive heart failure or arrhythmias even in absence of LVEF decrease. Hematologic assessment was done on days 1 and 12 of every cycle in arm A, and on days 1 and 14 in arm B, and whenever useful at discretion of investigator.

\section{Pretreatment and Follow Up Studies}

Pretreatment investigations included complete blood count and chemistry, chest $\mathrm{x}$-ray, bone scan, CT abdomen, LVEF evaluation by echocardiography, and other site-specific imaging as appropriate. Echocardiography with LVEF evaluation had to be performed every 3 cycles, or whenever indicated at discretion of investigator; during the follow-up LVEF had to be determined every 6 months.

\section{Evaluation of Response and Toxicity}

Tumor assessment was performed every 3 cycles, or whenever appropriate, and responses were evaluated according to RECIST criteria [31]. Progression free survival (PFS) was calculated starting from the date of randomization to the date of disease progression, refusal or death from any cause; overall survival (OS) was calculated starting from the date of randomization to the date of death or last follow up evaluation. Toxicity was assessed in each cycle according to National Cancer Institute Common Toxicity Criteria (version 3.0).

\section{Statistical Methods}

The primary objective of the study was to evaluate the overall response rate of the two regimens, secondarily toxicity, progression free survival and overall survival.
The study was designed as a phase II trial with a random assignement to a calibration arm $\mathrm{A}$ and to an experimental arm B. The sample size for arm B was calculated according to the design described by A'Hern [32]. A sample size of 53 patients was considered sufficient to give a $90 \%$ probability of rejecting a baseline response rate of $35 \%$ with an exact $5 \%$ one-sided significance test when the true response rate was $55 \%$. The drug regimen should have been considered for further studies if at least 25 responses were observed. The calibration arm had the same sample size. No formal comparison was planned. The objective response rate have been reported with its $95 \%$ confidence interval. All patients enrolled were considered in the intention-totreat population (ITT). This population have been evaluated for the efficacy analysis, which was performed also on evaluable patients. Subjects who assumed at least one dose of drug have been considered as denominator in the safety analysis.

The time to event analysis was performed according the Kaplan-Meier method.

\section{Results}

\section{Patients Characteristics}

From March 2003 to November 2005, a total of 104 patients were enrolled from 4 oncologic centers of the GOIM (Gruppo Oncologico Italia Meridionale), with 54 patients randomized to arm $\mathrm{A}$ (EPI/VNB) and 50 patients to arm B (PLD/VNB). All randomized patients have been evaluated for activity and toxicity according to ITT analysis. Patient characteristics are listed in Table 1. None of the patients have received any chemotherapy for advanced disease; 20 patients in arm $A$ and 21 patients in arm B had received adjuvant chemotherapy, not including anthracyclines or vinka alcaloids; 35 and 30 patients had received previous adjuvant hormonal therapy, and 10 and 11 patients had received endocrine treatment for advanced disease in $\operatorname{arm} \mathrm{A}$ and $\mathrm{B}$, respectively. Median age was 63 and 61 years, 10 and 9 patients were premenopausal, 44 and 41 postmenopausal in arm A and B, respectively; dominant site of disease was soft tissue in $3(5.6 \%)$ and $9(18.0 \%)$, bone in $11(20.4 \%)$ and 9 (18.0\%), viscera in $40(74.0 \%)$ and $32(64.0 \%)$ patients in arm A and B, respectively. Hormonal receptors were positive (ER and/or PgR) in 39 and 32 patients, negative in 13 and 15 patients, unknown in 2 and 3 patients in the two arms, respectively. Her-2, retrospectively evaluated in 35 and 38 patients in arm A and B, was overexpressed or amplified in 8 patients in each arm $(14.8 \%$ and $16 \%$, respectively). The median number of chemotherapy cycles administered was 6 in both arms (range, 1 to 8 in both arms). 
Table 1 Patient and tumor characteristics

\begin{tabular}{|c|c|c|c|c|}
\hline \multirow[t]{2}{*}{ Characteristics } & \multicolumn{2}{|c|}{ Arm $A(E V)=54$} & \multicolumn{2}{|c|}{ Arm B(PLD/V) $=50$} \\
\hline & No. & $\%$ & No. & $\%$ \\
\hline \multicolumn{5}{|l|}{ Age, years } \\
\hline Median & \multicolumn{2}{|c|}{63} & \multicolumn{2}{|c|}{61} \\
\hline Range & \multicolumn{2}{|c|}{$27-70$} & \multicolumn{2}{|c|}{$35-69$} \\
\hline Pre/Postmenopausal & \multicolumn{2}{|c|}{$10 / 44$} & \multicolumn{2}{|c|}{$9 / 41$} \\
\hline Median ECOGPS (range) & \multicolumn{2}{|c|}{$1(0-3)$} & \multicolumn{2}{|c|}{$1(0-3)$} \\
\hline \multicolumn{5}{|l|}{ *HR status } \\
\hline Positive & 39 & 72.2 & 32 & 64.0 \\
\hline Negative & 13 & 24.1 & 15 & 30.0 \\
\hline Unknown & 2 & 3.7 & 3 & 6.0 \\
\hline \multicolumn{5}{|l|}{ HER-2 status } \\
\hline \multicolumn{5}{|l|}{ Positive } \\
\hline \multicolumn{5}{|l|}{ Negative } \\
\hline \multicolumn{5}{|l|}{ Unknown } \\
\hline Prior adjuvant chemotherapy** & 20 & 37 & 21 & 42 \\
\hline \multicolumn{5}{|l|}{ Prior hormonal therapy } \\
\hline Adjuvant & 35 & 64.8 & 30 & 60 \\
\hline Advanced & 10 & 18.5 & 11 & 22 \\
\hline \multicolumn{5}{|l|}{ Disease free-interval (years) } \\
\hline$<1$ & 10 & & 11 & \\
\hline $1-5$ & 30 & & 28 & \\
\hline$>5$ & 14 & & 11 & \\
\hline \multicolumn{5}{|l|}{ Dominant disease site } \\
\hline Viscera & 40 & 74.0 & 32 & 64.0 \\
\hline Bone & 11 & 20.4 & 9 & 18.0 \\
\hline Soft tissue & 3 & 5.6 & 9 & 18.0 \\
\hline \multicolumn{5}{|l|}{ Number of disease site } \\
\hline 1 & 23 & 42.6 & 23 & 46.0 \\
\hline 2 & 23 & 42.6 & 18 & 36.0 \\
\hline$\geq 3$ & 8 & 42.6 & 9 & 18.0 \\
\hline
\end{tabular}

*HR: hormonal receptor status.

**not including anthracyclines or vinka alkaloids.

EV: epirubicin/vinorelbine; PLD/V: pegylated liposomal doxorubicin/vinorelbine.

\section{Efficacy}

According to an intent to treat analysis, among 54 patients enrolled in arm A, there were 3 complete response (5.6\%) and 20 partial responses (37\%), for an overall response rate of $42.6 \%$ (95\% CI, 29.3-55.9); disease remained stable in $19(35.2 \%)$, and progressive disease was observed in $6(11.1 \%)$ patients. Among 50 patients enrolled in arm $\mathrm{B}$, there were 8 complete responses (16\%) and 18 partial responses (36\%), for an overall response rate of $52 \%$ (95\% CI, 38.2-65.8); disease remained stable in $12(24 \%)$, and disease progression occurred in $9(18 \%)$ patients (Table 2a). Six patients of arm A and 3 patients of arm B were not evaluable for response (4 refusal, 5 lost to follow up). Objective response rates in 48 and 47 evaluable patients were 47.9\% (95\% CI, 33.9-61.9), and 55.3\% (95\% CI, 41.1-69.4)
Table 2 Objective responses

\begin{tabular}{|c|c|c|c|c|c|c|}
\hline \multicolumn{7}{|c|}{ 2a. ITT on all enrolled patients } \\
\hline & \multicolumn{3}{|c|}{ Arm A (EV) (54) } & \multicolumn{3}{|c|}{ Arm B (PLD/N) (50) } \\
\hline & No. & $\%$ & & No. & $\%$ & \\
\hline$C R$ & 3 & 5.6 & $42.6 \%$ & 8 & 16.0 & $52.0 \%$ \\
\hline PR & 20 & 37.0 & $42.6 \%$ & 18 & 36.0 & $52.0 \%$ \\
\hline NC & 19 & 35.2 & & 12 & 24.0 & \\
\hline PD & 6 & 11.1 & & 9 & 18.0 & \\
\hline
\end{tabular}

2b. On evaluable patients

\begin{tabular}{|c|c|c|c|c|c|c|}
\hline & \multicolumn{2}{|c|}{ Arm A (EV) (54) } & & \multicolumn{2}{|c|}{ Arm B (PLD/N) (47) } & \\
\hline & No. & $\%$ & & No. & $\%$ & \\
\hline$C R$ & 3 & 6.3 & $47.9 \%$ & 8 & 17.0 & $55.3 \%$ \\
\hline PR & 20 & 41.6 & $47.9 \%$ & 18 & 38.7 & $55.3 \%$ \\
\hline NC & 19 & 39.6 & & 12 & 25.5 & \\
\hline PD & 6 & 12.5 & & 9 & 19.2 & \\
\hline
\end{tabular}

2c. Overall response rates according to disease sites in evaluable patients (\%)

\begin{tabular}{lcc} 
& Arm A (EV) (48) & Arm B (PLDN) (47) \\
\hline Soft tissue & 66.6 & 77.7 \\
Bone & 33.3 & 37.5 \\
Viscera & 50. & 53.3 \\
\hline
\end{tabular}

Abbreviations: $\mathrm{EV}=$ epirubicin, vinorelbine; $\mathrm{PLD} / \mathrm{V}=$ pegylated liposomal doxorubicin/vinorelbine; $I T T=$ intent to treat; $C R=$ complete response; $P R=$ partial response; $\mathrm{NC}=$ no change; $\mathrm{PD}=$ progressive disease.

in the arm A and B, respectively (Table $2 \mathrm{~b}$ ). Disease control (CRs + PRs + NC) was $87.5 \%$ in arm A and $80.8 \%$ in $\operatorname{arm} \mathrm{B}$, respectively. Responses according to disease sites in evaluable patients are reported in details on Table 2c, and were as follows: arm A/B, soft tissue $66.6 \% / 77.7 \%$; bone $33.3 \% / 37.5 \%$; viscera $50 \% / 53.3 \%$. No relevant differences in response rate was observed according to hormonal receptor status, evidencing only a trend of higher response in receptor negative tumors in both arms (53.6\% vs $45.7 \%$, arm A; $60 \%$ and $53.1 \%$ arm B). No differences in response rates have been observed by Her-2 status in both arms, but numbers are very small: arm A Her-2 neg 54\%, Her-2 pos 42.8\%; arm B Her-2 neg 64\%, Her-2 pos $50 \%$. Median time to response was 2 months in both arms (range, 1 to 4 months). Median progression free survival (Figure 1) was 10.7 months in arm A (95\% CI, 8.7-12.6), and 8.8 months in arm B (95\% CI 7.1-10.5), median overall survival (Figure 2) was 34.6 months in arm A (95\%CI, 19.5-49.8) and 24.8 months in arm B (95\% CI, 15.7-33.9).

\section{Toxicity}

Table 3 summarizes treatment-related main toxicities. Overall, both treatment regimens were well tolerated. The dose-limiting toxicity was, as expected, myelosuppression, with G3-4 neutropenia occurring in $18.5 \%$ and $22 \%$ of the patients of arm A and B, respectively, with 


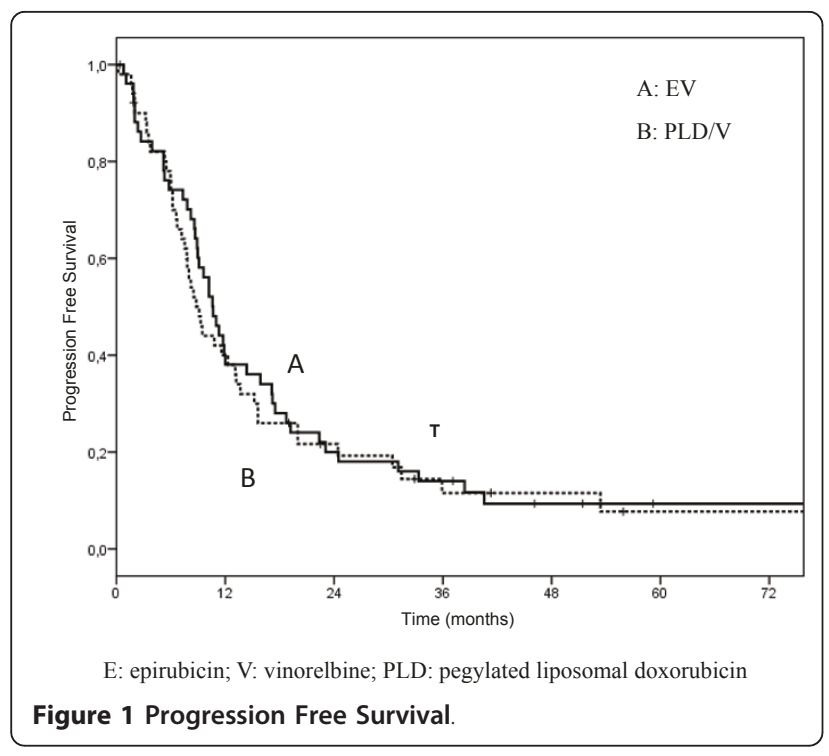

grade 3-4 neutropenic fever observed in 3 (5.5\%) patients of arm $\mathrm{A}$, and in 2 patients $(4.0 \%)$ of $\operatorname{arm~B}$, in whom the administration of G-CSF was required. A 25\% EPI/VNB dose-reduction was required in $7 \%$ of the patients, whereas a $25 \% \mathrm{PLD} / \mathrm{VNB}$ dose-reduction was required in 2 (4\%) patients. Grade 3 thrombocytopenia was encountered only in one patient in arm A. Grade 3 alopecia was universal in arm A, whereas in arm B it was of grade 3 only in $50 \%$ of the patients. Mild (G1-2) nausea and vomiting was encountered in $46.3 \% / 44.0 \%$ of the patients in the two arms, respectively. Grade 3 mucositis was observed in $7.4 \%$ and $12 \%$ of the patients in arm A and B, respectively. Reversible AST/ALT elevation was reported in 2 patients in both arms, and mild and transient peripheral neurotoxicity was observed in 8 and 7 patients in

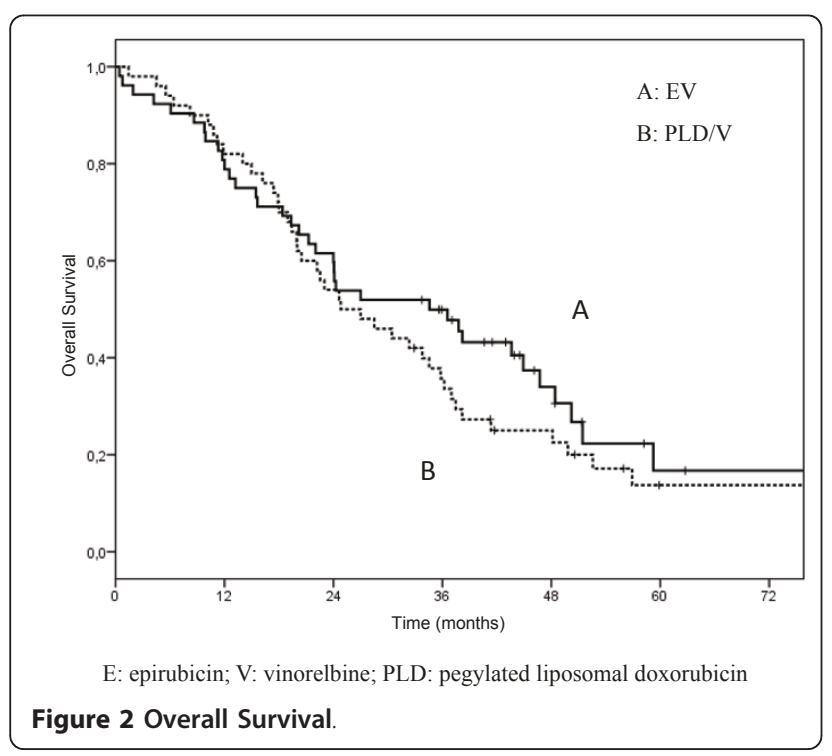

Table 3 Grade 3-4 NCI-CTC toxicities in 104 enrolled patients

\begin{tabular}{lcccc}
\hline & \multicolumn{2}{c}{ Arm A (EV = 54) } & \multicolumn{2}{c}{ Arm B (PLD/V = 50) } \\
\cline { 2 - 5 } & No. & \% & No. & $\%$ \\
\hline Anemia & 5 & 9.2 & 4 & 8 \\
Neutropenia & 10 & 18.5 & 11 & 22 \\
Thrombocytopenia & 1 & 1.8 & - & - \\
Febrile neutropenia & 3 & 5.5 & 1 & 2.0 \\
Hepatotoxicity & 2 & 3.7 & 2 & 4.0 \\
Mucositis & 4 & 7.4 & 6 & 12 \\
PPE/skin & - & - & 3 & 6 \\
Alopecia & 54 & 100 & 25 & 50 \\
Neurologic & 1 & 1.8 & 1 & 2.0 \\
Cardiac & 2 & 3.7 & - & - \\
\hline
\end{tabular}

Abbreviations: NCI-CTC: National Cancer Institute Common Toxicity Criteria; PPE: palmoplantar erithrodysthesia; EV: epirubicin/vinorelbine; PLD/V: pegylated liposomal doxorubicin/vinorelbine

arm A and B, respectively, while it was of grade 3 in 1 patients in both arms. Grade 3 PPE or cutaneous toxicity was observed in $3(6 \%)$ patients of arm B, usually related to treatment duration, and prompted to treatment discontinuation in 1 patient after 4 cycles. As cardiotoxicity concerns, no cases of congestive heart failure have been observed in the two arms. A transient and asymptomatic $\geq 20 \%$ LVEF decrease was encountered in 2 patients (3.7\%) in arm A, and this prompted to treatment discontinuation after $5^{\text {th }}$, and 6th cycle; complete LVEF recovery was observed in two months. One case of transient and reversible supraventricular tachyarrhythmia was observed in arm A, during the last EPI infusion. The median cumulative delivered EPI dose was $540 \mathrm{mg} / \mathrm{m}^{2}$ (range, 90 to $720 \mathrm{mg} / \mathrm{m}^{2}$ ); the median cumulative delivered PLD dose was $240 \mathrm{mg} / \mathrm{m}^{2}$ (range, 40 to $320 \mathrm{mg} / \mathrm{m}^{2}$ ). No toxic deaths have been observed in the two arms.

\section{Discussion}

Currently, there is no "gold standard" therapy for metastatic breast cancer, and treatment decisions must be based on patient and tumor characteristics, and on prior treatments. In the scenario of patients presenting with advanced disease, still exists a subgroup who have received only endocrine adjuvant therapy, or adjuvant chemotherapy with CMF or CMF-like regimens and, less frequently, there is a small cohort treated with adjuvant taxanes-based or other anthracycline-free regimens; moreover, there are also anthracycline pretreated patients with a very long free-interval, to be considered still anthracycline sensitive. In all these patient cohorts there is still the option to employ an anthracycline-based regimen as first-line treatment for advanced disease, mostly in hormonal receptor and/or Her-2 negative tumors, where a "targeted" therapy is not available. 
The results of the present study confirm the activity of both anthracycline-based chemotherapy regimens for anthracycline-naïve advanced breast cancer patients, even if lower than expected. Response rate, progression free survival and overall survival observed in experimental arm B were comparable to those obtained in the "calibration" EPI/VNB arm. As toxicity concerns, both regimens were tolerable, with a higher incidence of febrile neutropenia and G3 alopecia in arm A, and of grade 3 mucositis and cutaneous toxicity in arm B. As cardiotoxicity concerns, the relatively low cumulative EPI dose delivered $\left(\leq 720 \mathrm{mg} / \mathrm{m}^{2}\right)$ did not allow to evidence significant clinical cardiotoxicity in the arm A, with only one case of arrhythmia, and a transient and asymptomatic in LVEF decrease occurring in 2 patients (3.7\%), leading to a discontinuation of chemotherapy after 5 and 6 cycles, and with a complete recovery within two months.

Analyzing literature data, the EPI/VNB regimen is among the active, non-taxane, anthracycline-containing combinations for breast cancer treatment, as confirmed by definite results of the Scandinavian Breast Trial Group [33], and other trials [18], but some instances of clinical cardiac toxicity in terms of congestive heart failure or cardiomyopathy have been reported, with an incidence of asymptomatic LVEF decrease ranging from $20 \%-30 \%[33,34]$, so there is an urgent need of introduce new active and safer regimens for anthracycline-sensitive breast cancer patients, and a recent metanalysis showed a significant lower rate of both clinical and subclinical heart failure in patients treated with liposomal anthracyclines, compared with conventional doxorubicin [35].

A number of phase II trials have recently evaluated PLD in combination regimens with cyclophosphamide, paclitaxel, docetaxel, gemcitabine, VNB, and with biological agent such as trastuzumab or lapatinib, with response rates ranging from $31 \%$ to $75 \%$, frequently occurring even in anthracycline pretreated patients [36], and with negligible cardiotoxicity. In details, the PLD/ VNB combination was recently employed in two phase II trials in heavily pretreated patients, yielding a response rate of $36 \%$ and $39 \%$, without any cardiac toxicity $[37,38]$. Two more recent reports with PLD/VNB combination as first-line treatment in elderly patients confirmed the good overall clinical response rate $(36 \%$ and $50 \%$, respectively), and the high tolerability of the regimen [39,40] suggesting, due to the safety profile of the combination, the employment also in such "frail" patient population.

An increasingly pertinent question in patients relapsing following adjuvant anthracyclines is whether there is a role for anthracycline rechallenge in those with a long free-interval. As a result of a high cardiac risk associated with increasing cumulative anthracycline dose, patients are often denied re-treatment in advanced setting; the choice of a liposomal anthracycline allows the possibility of re-treating an anthracycline-responsive disease without substantially increasing the cardiac risk [36]; this option should not be excluded in fact, and some evidences come from a recent report on first- line chemotherapy selection in adjuvant anthracyclinepretreated patients, where no differences have been found between CMF-based and anthracycline-containing regimens for their impact on the outcome of first-line anthracycline treatment [41]. By this point of view, even if our results are in anthracycline-naïve patients, the activity and the low toxicity profile observed suggest that the choice of a liposomal formulation can offer the chance of a more tolerable regimen maintaing conventional anthracyclines efficacy.

The results of the present trial indicated both EPI/VNB and PLD/VNB as two reasonable choices as first-line treatment for women with relapsed breast cancer not previously treated with adjuvant anthracyclines; since advanced breast cancer is still an incurable disease, the goals of treatments are symptoms palliation with minimal toxicity, and survival prolongation, possibly with regimens active against cancer but also preserving patient's quality of life; in this context, our results are encouraging, confirming the feasibility and efficacy of two anthracycline-containing regimens and, particularly, of a regimen devoided of cardiac toxicity and of other severe side effects, such as PLD/VNB; the choice of this combination could offer a better quality of life and, hopefully, a better outcome to metastatic breast cancer patients.

\section{Conclusions}

Both anthracycline-based regimens evaluated as first-line treatment in advanced breast cancer patients not previously treated with anthracyclines seems to be active and well tolerated, and can be considered as a reasonable choice in this subset of patients

\section{Author details}

${ }^{1}$ Division of Medical Oncology B, Regina Elena National Cancer Institute, Rome, Italy. ${ }^{2}$ Department of Medical and Experimental Oncology, Oncologic Institute, Bari, Italy. ${ }^{3}$ Division of Medical Oncology, S. Francesco Hospital, Paola, Italy. ${ }^{4}$ Division of Surgery A, Regina Elena National Cancer Institute, Rome, Italy. ${ }^{5}$ Division of Gynecological Oncology, Regina Elena National Cancer Institute, Rome, Italy. ${ }^{6}$ Cardiologic Unit, Regina Elena National Cancer Institute, Rome, Italy. ${ }^{7}$ Biostatistics Unit, Regina Elena National Cancer Institute, Rome, Italy.

\section{Authors' contributions}

PV, GC, ML designed the study; FG, DS, GF, PP, CB, EV, AC, LP, AL, LDL collected and assembled the data, DG performed the statistical analysis, PV and LDL wrote the manuscript. All authors read and approved the final manuscript.

\section{Competing interests}

The authors declare that they have no competing interests. 
Received: 22 February 2011 Accepted: 12 April 2011

Published: 12 April 2011

\section{References}

1. Hamilton A, Hortobagyi G: Chemotherapy: what progress in the last 5 years? J Clin Oncol 2005, 23:1760-1775.

2. Lord S, Ghersi D, Gattellari M, Wortley S, Wilcken N, Simes J: Antitumour antibiotic containing regimens for metastatic breast cancer. Cochrane Database Syst Rev 2004, 18:CD003367.

3. Italian Multicentre Breast Study with Epirubicin: Phase III randomized study of fluorouracil, epirubicin, and cyclophosphamide vs fluorouracil, doxorubicin, and cyclophosphamide in advanced breast cancer: an Italian multicentre trial. J Clin Oncol 1988, 6:976-82.

4. Blomqvist C, Hietanen P, Teerenhovi L, Rissanen P: Vinorelbine and epirubicin in metastatic breast cancer. A dose finding study. Eur J Cancer 1995, 31:2406-2408.

5. Baldini E, Tibaldi C, Chiavacci F, Di Lieto M, Fioretto L, Giallom-bardo A, Taviani R, Ghezzi P, Bolognini A, Conte P: Epirubicin/vinorelbine as first line therapy in metastatic breast cancer. Breast Cancer Res Treat 1998, 49:129-134.

6. Bonadonna G, Gianni L, Santoro A, Bonfante V, Bidoli P, Casali P, Demicheli R, Valagussa P: Drugs ten years later: epirubicin. Ann Oncol 1993, 4:359-369.

7. Focan $C$, Andrien JM, Closon MT, Dicato M, Driesschaert P, FocanHenrard D, Lemaire M, Lobelle JP, Longree L, Ries F: Dose-response relationship of epirubicin-based first-line chemotherapy for advanced breast cancer: a prospective randomized trial. J Clin Oncol 1993, 11:1253-1263.

8. French Epirubicin Study Group: A prospective randomized phase III trial comparing combination chemotherapy with cyclophosphamide, fluorouracil, and either doxorubicin or epirubicin. J Clin Oncol 1988, 6:679-688

9. Brufman G, Colajori E, Ghilezan N, Lassus M, Martoni A, Perevodchikova N, Tosello C, Viaro D, Zielinski C: Doubling epirubicin dose intensity (100 $\mathrm{mg} / \mathrm{m}^{2}$ versus $50 \mathrm{mg} / \mathrm{m}^{2}$ ) in the FEC regimen significantly increases response rates. An international randomised phase III study in metastatic breast cancer. The Epirubicin High Dose (HEPI 010) Study Group. Ann Oncol 1997, 8:155-162.

10. Lopez M, Vici P, Di Lauro K, Conti F, Paoletti G, Ferraironi A, Sciuto R, Giannarelli D, Maini CL: Randomized prospective clinical trial of high-dose epirubicin and dexrazoxane in patients with advanced breast cancer and soft tissue sarcomas. J Clin Oncol 1998, 16:86-92.

11. Fumoleau P, Delgado FM, Delozier T, Monnier A, Gil Delgado MA, Kerbrat P, Garcia-Giralt E, Keiling R, Namer M, Closon MT: Phase II trial of weekly intravenous vinorelbine in first-line advanced breast cancer chemotherapy. J Clin Oncol 1993, 11:1245-1252.

12. Gasparini G, Caffo O, Barni S, Frontini L, Testolin A, Guglielmi RB, Ambrosini $\mathrm{G}$ : Vinorelbine is an active antiproliferative agent in pretreated advanced breast cancer patients: a phase II study. J Clin Oncol 1994, 12:2094-2101.

13. Spielmann $M$, Dorval $T$, Turpin $F$, Antoine E, Jouve M, Maylevin F, Lacombe D, Rouesse J, Pouillart P, Tursz T: Phase II trial of vinorelbine/ doxorubicin as first-line therapy of advanced breast cancer. J Clin Oncol 1994, 12:1764-1770.

14. Blajman C, Balbiani L, Block J, Coppola F, Chacon R, Fein L, Bonicatto S, Alvarez A, Schmilovich A, Delgado FM: A prospective, randomized Phase III trial comparing combination chemotherapy with cyclophosphamide, doxorubicin, and 5-fluorouracil with vinorelbine plus doxorubicin in the treatment of advanced breast carcinoma. Cancer 1999, 85:1091-1907.

15. Namer M, Soler-Michel P, Turpin F, Chinet-Charrot P, de Gislain C, Pouillart P, Delozier T, Luporsi E, Etienne PL, Schraub S, Eymard JC, Serin D, Ganem G, Calais G, Maillart P, Colin P, Trillet-Lenoir V, Prevost G, Tigaud D, Clavère $P$, Marti $P$, Romieu $G$, Wendling JL: Results of a phase III prospective, randomised trial, comparing mitoxantrone and vinorelbine (MV) in combination with standard FAC/FEC in front-line therapy of metastatic breast cancer. Eur J Cancer 2001, 37:1132-1140.

16. Norris B, Pritchard Kl, James K, Myles J, Bennett K, Marlin S, Skillings J, Findlay B, Vandenberg T, Goss P, Latreille J, Rudinskas L, Lofters W, Trudeau M, Osoba D, Rodgers A: Phase III comparative study of vinorelbine combined with doxorubicin versus doxorubicin alone in disseminated metastatic/recurrent breast cancer: National Cancer
Institute of Canada Clinical Trials Group Study MA8. J Clin Oncol 2000, 18:2385-2394.

17. Ejlertsen B, Mouridsen HT, Langkjer ST, Andersen J, Sjostrom J, Kjaer M: Improved progression-free survival from the addition of vinorelbine to epirubicin in first line chemotherapy of metastatic breast cancer. Breast Cancer Res Treat 2001, 69:270, (abstract 355.2001).

18. Vici P, Colucci G, Gebbia V, Amodio A, Giotta F, Belli F, Conti F, Gebbia N, Pezzella G, Valerio MR, Brandi M, Pisconti S, Durini E, Giannarelli D, Lopez M: First-line treatment with epirubicin and vinorelbine in metastatic breast cancer. J Clin Oncol 2002, 20:2689-94.

19. Vici P, Foggi P, Colucci G, Capomolla E, Brandi M, Giotta F, Gebbia N, Di Lauro L, Valerio MR, Paoletti G, Belli F, Pizza C, Giannarelli D, Lopez M: Sequential docetaxel followed by epirubicin-vinorelbine as first-line chemotherapy in advanced breast cancer. Anticancer Res 2005, 25:1309-1314.

20. Brown JM, Giaccia AJ: The unique physiology of solid tumors: opportunities (and problems) for cancer therapy. Cancer Res 1998 58:1408-1416.

21. Batist G, Ramakrishnan G, Rao CS, Chandrasekharan A, Gutheil J, Guthrie T, Shah P, Khojasteh A, Nair MK, Hoelzer K, Tkaczuk K, Park YC, Lee LW: Reduced cardiotoxicity and preserved antitumor efficacy of liposomeencapsulated doxorubicin and cyclophosphamide compared with conventional doxorubicin and cyclophosphamide in a randomized, multicenter trial of metastatic breast cancer. J Clin Oncol 2001, 19:1444-1454

22. Harris $L$, Batist $G$, Belt R, Rovira D, Navari R, Azarnia N, Welles L, Winer E, TLC D-99 Study Group: Liposome-encapsulated doxorubicin compared with conventional doxorubicin in a randomized multicenter trial as first-line therapy of metastatic breast carcinoma. Cancer 2002, 94:25-36.

23. Chan S, Davidson N, Juozaityte E, Erdkamp F, Pluzanska A, Azarnia N, Lee LW: Phase III trial of liposomal doxorubicin and cyclophosphamide compared with epirubicin and cyclophosphamide as first-line therapy for metastatic breast cancer. Ann Oncol 2004, 15:1527-1534.

24. O'Brien MER, Wigler N, Inbar M, Rosso R, Grischke E, Santoro A, Catane R, Kieback DG, Tomczak P, Ackland SP, Orlandi F, Mellars L, Alland L, Tendler C: Reduced cardiotoxicity and comparable efficacy in a phase III trial of pegylated liposomal doxorubicin $\mathrm{HCl}\left(\mathrm{CAELYX}^{\mathrm{TM}} /\right.$ Doxil $\left.^{\oplus}\right)$ versus conventional doxorubicin for first-line treatment of metastatic breast cancer. Ann Oncol 2004, 15:440-449.

25. van Dalen EC, Michiels EM, Caron HN, Kremer LC: Different anthracycline derivates for reducing cardiotoxicity in cancer patients. Cochrane Database Syst Rev 2010, 5:CD005006.

26. Keller AM, Mennel RG, Georgoulias VA, Nabholtz JM, Erazo A, Lluch A, Vogel CL, Kaufmann M, von Minckwitz G, Henderson IC, Mellars L, Alland L, Tendler C: Randomized phase III trial of pegylated liposomal doxorubicin versus vinorelbine or mitomycin C plus vinblastine in women with taxane-refractory advanced breast cancer. J Clin Oncol 2004, 22:3893-3901.

27. Lorusso V, Manzione L, Silvestris N: Role of liposomal anthracyclines in breast cancer. Ann Oncol 2007, 6:70-73.

28. Safra T, Muggia F, Jeffers $S$, Tsao-Wei DD, Groshen S, Lyass O, Henderson R, Berry G, Gabizon A: Pegylated liposomal doxorubicin (doxil): reduced clinical cardiotoxicity in patients reaching or exceeding cumulative doses of $500 \mathrm{mg} / \mathrm{m}^{2}$. Ann Oncol 2000, 11:1029-1033.

29. Gebbia V, Mauceri G, Fallica G, Borsellino N, Tirrito ML, Testa A, Varvara F, Colombo A, Ferrera P: Pegylated liposomal doxorubicin with vinorelbine in metastatic breast carcinoma. A phase I-II clinical investigation. Oncology 2002, 63:23-30.

30. Martin M, García-Donas J, Casado A, de la Gándara I, Pérez-Segura P, GarcíaSaenz JA, Ibáñez G, Loboff B, García-Ledo G, Moreno F, Grande E, DiazRubio E: Phase II study of pegylated liposomal doxorubicin plus vinorelbine in breast cancer with previous anthracycline exposure. Clin Breast Cancer 2004, 5:353-357.

31. Therasse P, Arbuck SG, Eisenhauer EA, Wanders J, Kaplan RS, Rubinstein L, Verweij J, Van Glabbeke M, van Oosterom AT, Christian MC, Gwyther SG: New guidelines to evaluate the response to treatment in solid tumors. European Organization for Research and Treatment of Cancer, National Cancer Institute of the United States, National Cancer Institute of Canada. J Natl Cancer Inst 2000, 92:205-216.

32. A'Hern RP: Sample size tables for exact single-stage phase II designs. Stat Med 2001, 20:859-866. 
33. Ejlertsen B, Mouridsen HT, Langkjer ST, Andersen J, Sjöström J, Kjaer M, Scandinavian Breast Group Trial (SBG9403): Phase III study of intravenous vinorelbine in combination with epirubicin versus epirubicin alone in patients with advanced breast cancer: a Scandinavian Breast Group Trial (SBG9403). J Clin Oncol 2004, 22:2313-2320.

34. Nisticò C, Garufi C, Barni S, Frontini L, Gallà DA, Giannarelli D, Vaccaro A, D'Ottavio AM, Terzoli E: Phase II study of epirubicin and vinorelbine with granulocyte colony-stimulating factor: a high-activity, dose-dense weekly regimen for advanced breast cancer. Ann Oncol 1999, 10:937-942.

35. van Dalen EC, Michiels EM, Caron HN, Kremer LC: Different anthracycline derivates for reducing cardiotoxicity in cancer patients. Cochrane Database Syst Rev 2010, 12:CD005006.

36. Verma S, Dent S, Chow BJ, Rayson D, Safra T: Metastatic breast cancer: the role of pegylated liposomal doxorubicin after conventional anthracyclines. Cancer Treat Rev 2008, 34:391-406.

37. Chow LW, Yip AY, Lang BH: A phase II trial of vinorelbine and pegylated liposomal doxorubicin in patients with pretreated metastatic breast cancer. Am J Clin Oncol 2007, 30:133-138.

38. Ardavanis A, Mavroudis D, Kalbakis K, Malamos N, Syrigos K, Vamvakas L, Kotsakis A, Kentepozidis N, Kouroussis C, Agelaki S, Georgoulias V: Breast Cancer Committee of the Hellenic Oncology Research Group. Pegylated liposomal doxorubicin in combination with vinorelbine as salvage treatment in pretreated patients with advanced breast cancer: a multicentre phase II study. Cancer Chemother Pharmacol 2006, 58:742-748.

39. Mlineritsch B, Schabel-Moser R, Andel J, Fridrik M, Moik M, Mayer P, Russ G, Rass C, Greil R, Arbeitsgemeinschaft medikamentöse Tumortherapie Study Group: Multicenter phase II study of pegylated liposomal doxorubicin in combination with vinorelbine as first-line treatment in elderly patients with metastatic breast cancer. Onkologie 2009, 32:18-24

40. Addeo R, Faiola V, Guarrasi R, Montella L, Vincenzi B, Capasso E, Cennamo G, Rotundo MS, Tagliaferri P, Caraglia M, Del Prete S: Liposomal pegylated doxorubicin plus vinorelbine combination as first-line chemotherapy for metastatic breast cancer in elderly women $>$ or $=65$ years of age. Cancer Chemother Pharmacol 2008, 62:285-292.

41. Morabito A, Piccirillo MC, Monaco K, Pacilio C, Nuzzo F, Chiodini P, Gallo C, de Matteis A, Perrone F, NCl Naples Breast Cancer Group: First-line chemotherapy for HER-2 negative metastatic breast cancer patients who received anthracyclines as adjuvant treatment. Oncologist 2007, 12:1288-1298

doi:10.1186/1756-9966-30-39

Cite this article as: Vici et al:: A multicenter prospective phase II randomized trial of epirubicin/vinorelbine versus pegylated liposomal doxorubicin/vinorelbine as first-line treatment in advanced breast cancer. A GOIM study. Journal of Experimental \& Clinical Cancer Research 2011 30:39.

\section{Submit your next manuscript to BioMed Central and take full advantage of:}

- Convenient online submission

- Thorough peer review

- No space constraints or color figure charges

- Immediate publication on acceptance

- Inclusion in PubMed, CAS, Scopus and Google Scholar

- Research which is freely available for redistribution 